19. Saturn. Major axis outer ring $=37^{\prime \prime} 74$. Minor axis $=9^{\prime \prime} \cdot 05$.

20-22. Epoch of April meteors (Lyrids, radiant $271^{\circ}+33^{\circ}$ ).

2I. $8 \mathrm{~h}$. Mercury at greatest elongation east $20^{\circ} \mathrm{II}^{\prime}$.

22. 22h. Venus in conjunction with Jupiter. Venus $0^{\circ} 30^{\prime} \mathrm{S}$.

27. I 2h. 20m. Minimum of Algol ( $\beta$ Persei).

3o. $9 \mathrm{~h} .9 \mathrm{~m}$. Minimum of Algol ( $\beta$ Persei).

"I $\quad$ $8 \mathrm{~h} .32 \mathrm{~m}$. Transit (egress) of Jupiter's Sat. III. (Ganymede).

Standard Velocity Stars.-In a communication to No. 2, vol. xix., of the Astrophysical Journal, M. A. Belopolsky gives an account of the work which has been done at Pulkowa in connection with the international cooperative scheme for the determination of the radial velocities of certain standard stars.

The 36-inch refractor and a new Töpfer spectrograph, similar to the Potsdam IIIa. spectrograph, have been used, and the details of the methods employed and of the provisional results obtained, for six of the velocity stars, are given in the present paper. The results are not so good as might be expected, but it is hoped that better results will be attained during the next year's work. The spectrum of iron was used for comparison, and control spectrograms of the sun, Mars, Jupiter and Venus were obtained. The results for the first three are discussed in the present paper; those for Venus, which are much more comprehensive, are being reserved for a future communication.

Observed Motions in the Nova Perset Nebula.-Prof. J. M. Schaeberle, in a note to the Astronomische Nachrichten (No.3935), points out the great importance of studying every possible condition which may affect the determination of the parallax of the nebula surrounding Nova Persei, for until the parallax is unquestionably known theories regarding the observed movements can only be of a highly speculative character. In determining the actual parallax only the "absolute" method is available, and Prof. Schaeberle suggests that one of the conditions affecting the results might possibly be a refraction of the rays by some interplanetary medium filling the solar system. He contends that it is only reasonable to suppose that a difference of some kind may exist between the space void of heated matter and that surrounding an attracting mass radiating both matter and heat. If any medium (either gaseous or ethereal), such as an extended solar atmosphere, does exist, then any light entering such a space would be refracted, and the hitherto determined negative parallaxes are simply the differences between this refraction and the true parallax, where the latter is less than the former; similarly in cases where the measures indicate no parallax the two may be equal and opposite. Thus if this refraction constant were only $\mathrm{I}^{\prime \prime}$ the recorded motions in the nebulosity surrounding Nova Persei would be readily explicable, for with a parallax of $I^{\prime \prime}$ they are about equal in magnitude to those occasionally observed in solar work.

A New Form of Equatorial Mounting.-A new form of equatorial mounting, for which the inventor, Herr A. F. Lindemann, of Darmstadt, claims many advantages, is described and illustrated by a diagram in No. 3935 of the Astronomische Nachrichten.

The light from the star is collected by an objective placed at the upper end of the polar axis, and by a system of mirrors is reflected down that axis. By suitable mechanism the movements in R.A. and declination are imparted to tubes inside the telescope (i.e. the polar axis), and hence to the reflectors, from clockwork of the usual form.

Among the many advantages claimed for this form of mounting are that the observer may remain comfortably seated in a room of uniform temperature, the instrument is very compact and perfectly balanced, the vibration effects are reduced to a minimum, and no large dome with costly mechanism for revolving it is required.

The LeONid Shower of 1903.- Further avidence that the Leonid shower of 1903 afforded a fairly rich display is given by the observations made at the Royal Observatory at Lisbon. During a watch of $3 \mathrm{~h} .28 \mathrm{~m}$. $(15 \mathrm{~h} .14 \cdot 7 \mathrm{~m}$. to 84. 42.7m. G.M.T.) on November 15, Senor Campos No. I 796, VOL. 69]
Rodrigues counted $16_{5}$ Leonids. At the maximum of the shower during the five minutes' interval from $16 \mathrm{~h} .46 .7 \mathrm{~m}$. to 16h. $5 \mathrm{r} \cdot 7 \mathrm{~m} .22$ Leonids were counted (Astronomische Nachrichten, No. 3936).

THE INSTITUTION OF NAVAL ARCHITECTS.

THE annual general meeting of the Institution of Naval Architects was held last week in the theatre of the Society of Arts, the president, the Earl of Glasgow, occupying the chair. The meeting commenced on the morning of Wednesday, March 23, and was carried on during the two following days. There was on the agenda a list of fourteen papers to be read and discussed, and these, being all dealt with, made, together with the presidential address and other business, a very full programme for each day, possibly ton full, considering the sittings did not commence until noon.

As president of the institution, Lord Glasgow yearly gives a general summary of the condition of the shipbuilding and marine engineering industries of the country in his address, which, though brief, contains a quantity of matter which well illustrates Huxley's apothegm as to the need of knowing a great deal to say a little well. His remarks on the future of the steam turbine, on the prospects of internal combustion engines, and on other matters of a like nature indicate that Lord Glasgow is more than a merely ornamental president.

The chief interest in the meeting was doubtless centered in Sir Edward Reed's paper on the two battleships recently purchased from the Chilian authorities by our own Admiralty. These two ships, now H.M.S. Triumph and Swiftsure-formerly the Libertad and the Constitucionwere designed by Sir Edward Reed in conjunction with officers of the Chilian Navy. The debates in Parliament, in which the designs of these vessels were compared with those of battleships of the Royal Navy, raised considerable feeling, and the personal element, which always attracts interest, was not absent. It cannot be said, however, that either the paper or the discussion did much to advance the science of warship design. Sir Edward Reed maintained the superiority of his own designs, whilst Sir William White, who was the chief speaker in the discussion, upheld the superior advantages of the ships for which he was responsible. At present the efficiency of designs for warships is an open question upon which critics may hold conficting opinions without fear of them being proved erroneous, and this position is likely to continue until practical evidence is obtained by the test of actual warfare. Beyond this, however, it is seldom-in fact one may say never-that particulars sufficient for a full comparison of different ships are made public, and it is for these reasons that the controversies in warship design are so barren.

A paper by Lord Brassey which followed, and dealt with the problem of merchant cruisers and steamship subsidies, pointed out the need that would arise in case of war for more scouts than the navy at present possesses, and advocated the use of merchant vessels for this purpose. Here naval opinion was divided, one authority, Admiral Fitzgerald, maintaining that it would be better policy to devote any money available to the building of regular warships rather than to paying subsidies, whilst another admiral Sir Edmund Fremantle, said that if he had to send a vessel at full speed across the ocean he would select an Atlantic liner, as our cruisers would not be able to maintain so high a speed for so long a period as the mercantile vessel. The question of portable armour, to be shipped in case of war on merchant vessels, was also brought forward, but this was fully discussed by Prof. Biles at a meeting of the institution held just ten years ago.

On the second day of the meeting Sir William White read a paper in which he advocated the establishment of an experimental tank for testing ships' forms by means of models, on the system instituted by the late William Froude at Torquay. At the Glasgow meeting of the institution held in I90I, Mr. Yarrow brought forward a motion proposing that a tank should be established under the auspices of the institution. As a result efforts were made to raise the necessary funds, but although some ship-building firms promised handsome subscriptions, the proposal was not well 
backed up. The reason for the failure was attributed to the fact that it was proposed to try models for different firms, and it was feared that difficulties might arise. Sir William now suggests that what might be called the commercial side of the scheme should be abandoned, and that a tank should be constructed for the sole purpose of research work, and investigation into the general principles underlying the science of naval architecture. This would naturally cut off the income it was proposed should be derived from testing models for firms, and therefore a sufficient sum must be collected, not only to build the tank, but also to endow it. The suggestion is that the tank should be constructed at Bushy, and be incorporated as a part of the National Physical Laboratory. The cost of building would be about ${ }^{15} 5$,oool., and the annual cost of staff, maintenance, \&c., would be about $1500 l$. Dr. Glazebrook, who spoke in the discussion, said the management of the National Physical Laboratory welcomed the suggestion most cordially, and it therefore only remains to collect the money. The cooperation of ship owners, as well as of ship builders, was asked for, and the general opinion of the meeting appeared to be that it would argue ill for the enterprise and public spirit of the shipping community if the moderate sum needed were not forthcoming.

The next paper read was doubtless the most valuable presented at the meeting. It was a contribution by Mr. R. E. Froude, and detailed some results on model experiments. It is hardly necessary to remind our readers that Mr. Froude has for many years carried on at Haslar for the Government the work in connection with tank research inaugurated by his brilliant father. The details he now gives are the result of experiments carried through a period of thirty years; in fact, the initial trials were made at Torquay by the late Mr. Froude. The details given were of a purely technical nature, and could not be explained without the advantage of much space and many diagrams of ships forms, \&c. Although the details referred to war vessels, they are applicable to mercantile craft within the limits of form included.

A paper by Prof. Scribanti, of the Royal Italian Navy, on the heeling and rolling of ships of small initial stability, was read in brief abstract, and was not discussed.

A paper by Herr Otto Schlick, on the gyroscopic effect of fly wheels on board ship, was read at the evening sitting of Thursday. The author proposed the installation of an enormous gyroscope for the purpose indicated. The suggestion is not new, but the practical difficulties in the way have generally been considered too great to make the plan acceptable to ship designers. Herr Schlick's paper was, however, acceptable as giving in simple language an admirable exposition of the gyroscopic effect.

Two papers, respectively by Mr. J. E. Thornycroft and Mr. A. F. Evans, gave particulars, chiefly of a historical nature, of the application of oil engines to small vessels. The occasion is perhaps notable from the fact that some members present, connected in a practical manner with marine engineering and ship design, considered the use of gas engines for marine propulsion-with gas producers in place of steam boilers-as a problem that would have to be considered before long.

At the Friday meeting Prof. Plateau, of Paris, gave particulars of vessels fitted with the form of steam turbine he has invented, notably a first-class torpedo boat built by Messrs. Yarrow and Co. This vessel has made a speed of 26.39 knots. The battle of the turbines is likely to be the great feature in the domain of ship propulsion in the immediate future. Whether the impulse type or the reaction type will prove superior is a question that must be settled by experiment, and further information on this subject is anticipated with interest. The adoption of the steam turbine in the two new Cunard liners, after an exhaustive inquiry by a very competent tribunal, has placed the steam turbine on a firm basis as a means of marine propulsion.

A paper by Dr. J. Bruhn, on some points in connection with the transverse strength of ships, dealt with a problem of such complexity that it has often been considered indeterminable; whilst a second paper by Mr. A. W. Johns, on the normal pressure on thin moving plates, is also one that lends itself to abstruse mathematical consideration.

NO. I 796, vOI. 69]

\section{RECENT DISCOVERIES IN BACTERIOLOGY.'}

THESE are researches towards a fuller knowledge of the morphology and life-history of various orders belonging to Bacteriaceæ. So far the complete life-history of sporogenous forms had only been worked out for a very small number, all belonging to the genus Bacillus. The discovery of spores in the genus Sarcina, and the acquisition of a pure culture of the same by the author, gave him an opportunity of making a complete investigation of this genus. It includes the treatment of spores with various reagents, the germination, the mode of insertion of cilia, the course of development in various media, mode of celldivision, development of spores, and a number of physiological experiments. With appropriate stains the morphology and inner structure of the cell was examined, the cell being differentiated into membrane cytoplasm and nucleus. The results of metabolism fat, glycogen, \&c., were not observed, so the products of protoplasm must be dissolved in the cytoplasm, and cannot at present be examined microscopically. The development of the spore is interesting, and requires a very delicate manipulation of stains. It first appears as a vacuole with a central nucleus embedded in it. The vacuole gets denser, until the young spore now dimly outlined stains more deeply than the neighbouring cytoplasm. Then it differentiates a membrane and gradually becomes very strongly refractive, whilst the rest of the cell almost entirely disappears, being only visible when treated with certain stains. This description tallies with Meyer's account of the development of the spore in the genus Bacillus.

Investigation was also carried into the genus Spirillum, the species Sp. giganteum being chosen. The variation of size and form, variation, nature, and amount of reserve matter (fat and "Volutans-kugeln"'), the ciliation, the course of development in various media, pathogenic structures, \&c., were fully examined, so that a complete diagnosis of the species is in our possession. The formation of spores is unfortunately as yet unknown in this species. In this species the most interesting result was the demonstration of the origin of the cilia from the inside of the cell. Some investigators had maintained that the cell had no membrane, beng simply naked protoplasm, and that the cilia arose from the periphery, others that there was a membrane, so that the cilia must arise from the inside. The whole question was purely conjectural, but with appropriate staining, which is given in the text, and shown by drawings, the author proves the latter hypothesis to be the true one.

The most important part of the above researches is that dealing with ciliation. Modern classification subdivides according to the possession or non-possession of organs of motion. It is proved that formation of slime in the artificial cultures of the laboratory is the cause of absence of motion. A method is discovered to prevent this formation, with the result that all the supposed non-motile forms were found to be motile, and from everyone the organs of motion were successfully demonstrated. The investigation included I 7 forms from the genus Sarcina, 5 forms from the genus Micrococcus, 3 forms from the genus Streptococcus, and 5 from the genus Bacterium, all indiscriminately chosen. Hence the genus Sarcina is absolutely identical with the genus Planosarcina, Micrococcus with Planococcus, and Bacterium with Bacillus (see Migula's "System der Bakterien "). It is therefore obviously necessary that the subdivision of the families Coccacæ and Bacteriaceæ must be remodelled. A new classification is proposed for these two families, the essence of which is as follows:-

\section{Family Coccaceae. Round cells, ciliated.}

(I) Genus Streptococcus. Division in one direction of space.

(2) Genus Micrococcus. Division in two directions of space.

(3) Genus Sarcina. Division in three directions of space.

1 (I) "Untersuchungen über Sarcina Streptoccus und Spirillum," Centralblatt fiür Bakteriologie, Abt. I. Bd. XXXIII. (Igo3.) (2) "Der Nachweis

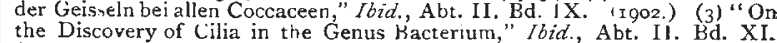
(rgo3.) No.8/9. By David Ellis, Ph.D. (Marburg), B.Sc. (London). 